\title{
Influence of cover depth towards quantitative size estimation of delaminations in external wall using passive infrared thermography
}

\author{
by S. Y. Chiu*, Wallace W. L. Lai*, C. Janet F. C. Sham*, Miranda C. Y. Lui**
}

*The Hong Kong Polytechnic University, The Department of Land Surveying and Geo-informatics, Hong Kong, sin-yau-lydia.chiu@connect.polyu.hk, wallace.wai.lok.lai@polyu.edu.hk and janet.sham@poly.edu.hk

** MES Group Asia, Unit D, 16/F, Nathan Commercial Building, 430 Nathan Road, Yaumatei, Kowloon, Hong Kong., mirandalui@mesgroup.asia

\begin{abstract}
This paper validates the use of passive infrared thermography in size estimation of delaminations in external wall with various finishing materials and the influence of the cover depth of delaminations. Thermograms of a reinforced concrete wall surface with embedded delaminations in different depths were collected in 10-hr diurnal experiments and processed in an in-house program with a modified gradient algorithm. This paper reports the accuracy of the proposed size estimation method and how cover depth could affect the observed signals of delamination in thermograms in reflecting its actual size.
\end{abstract}

\section{Introduction}

In Hong Kong, buildings aged 30 years or above are required to carry out building inspection and passive infrared thermography is one of the inspection methods adopted. Lai et al. [1] stated that passive infrared thermography could be used to detect delaminations in construction materials in a full-field, non-contact and non-destructive approach. Maldague [2] verified that the thermal contrast between a delamination and the intact area could be considered as a hot spot with 1 $2^{\circ} \mathrm{C}$ difference, and thermal contrast over $4^{\circ} \mathrm{C}$ can confirm the presence of a delamination. Uneven temperature distribution on building envelop could hence be identified as delaminations. However, buildings envelop are covered with different finishing materials. Avdelidis and Moropoulou [3] suggested that materials with lower emissivity may reflect temperatures of nearby objects while materials with higher emissivity enable more heat absorption and emission. Hence, the accuracies of quantitative size estimation adopting passive infrared thermography could be affected by the building finishing materials. In this study, a reinforced concrete wall was divided into 8 parts with different wall composite finishes. Thermograms of the wall surface were collected and processed in an in-house program with a modified gradient algorithm developed based on the study of Lai's et. al [4]. Hence, size of the suspected delaminations could be estimated. The proposed method evaluates the influence of cover depth on delamination size estimation.

\section{Experiment Set-up}

The reinforced concrete wall used in this study is divided into 8 parts. 7 parts were covered with ceramic tiles and mosaic tiles in different colours and textures while 1 part was finished with rendering. Fig 1(a) shows the details of different finishing materials covered on the reinforced concrete wall. 5 low-density polystyrene foam plates were embedded in cover depth of $5 \mathrm{~mm}, 8 \mathrm{~mm}, 15 \mathrm{~mm}$ and $17 \mathrm{~mm}$ in each part as shown in Fig. 1(b).

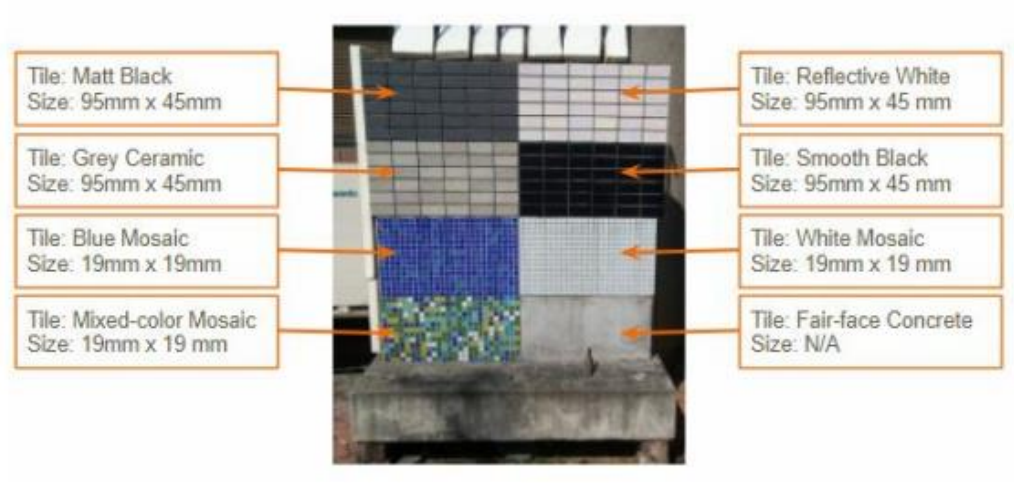

(a)

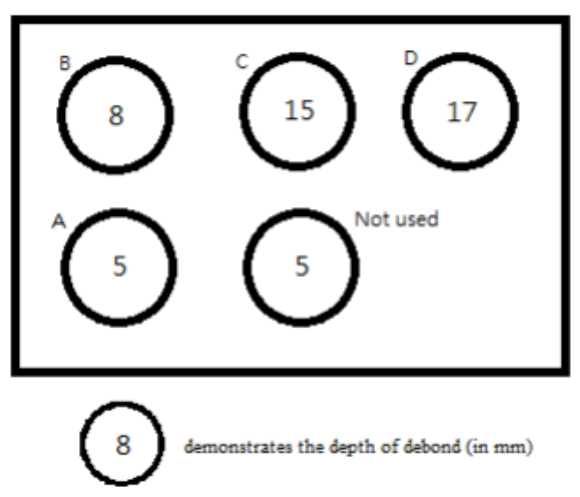

(b)

Fig. 1: (a) Details of different finishing materials on the reinforced concrete wall and (b) Demonstration of delamination with depth 
Experiments were conducted in outdoor environment to allow even sunlight absorption to the reinforced concrete wall. Thermograms of the target wall were captured with an infrared camera FLIR T650sc which was set up at $2.5 \mathrm{~m}$ from the wall in every 5 mins.

\section{Results and Discussion}

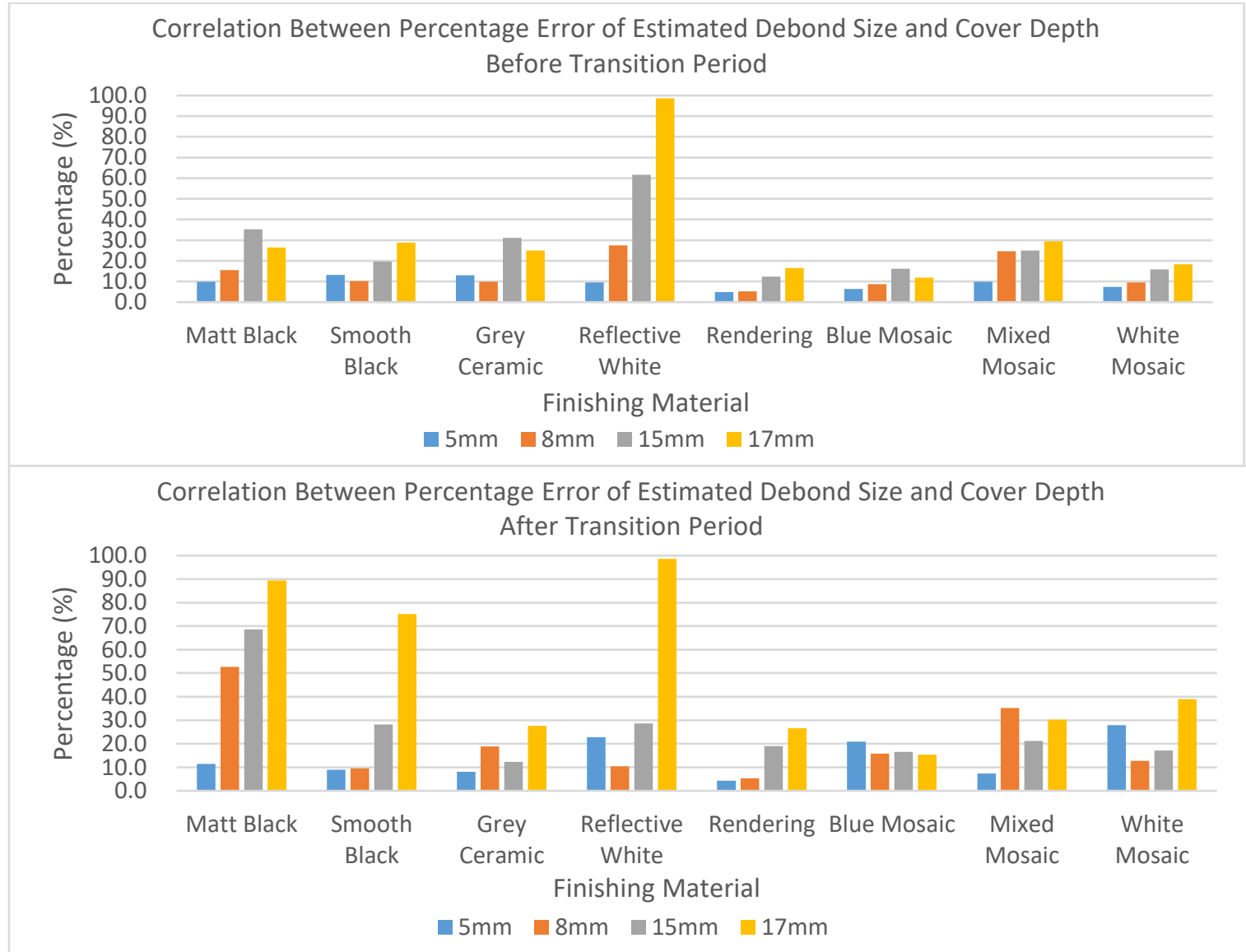

Fig. 2: Correlation Between Percentage Error of Estimated Debond Size and Cover Depth Before and After Transition Period

The results show that a transition period appears from around 16:00 to 17:00 where the delaminations begin to change from hot spots to cold spots, and the transition period may differ in finishing materials. During the transition period, the thermal contrast between the debond area and the intact area is insignificant, and hence only thermograms before and after the transition period are used in data analysis. The correlation between absolute percentage error of estimated debond sizes and the cover depth are presented in Fig. 2.

In Fig. 2, the accuracies of the size estimation in cover depth of $5 \mathrm{~mm}$ before transition period where debonds are shown as hot spots is within $10 \%$ while deeper cover depth (i.e. $15 \mathrm{~mm}$ and $17 \mathrm{~mm}$ ) is between $20-30 \%$. This indicates that shallower cover depth (within $5 \mathrm{~mm}$ ) has a higher accuracy on size estimation where the accuracy varies with materials of wall finishes. Under the same wall finishing materials, the size of hot spot in shallower cover depth is close to actual size while the size of hot spot in deeper cover depth is relatively over-estimated. Delaminations in deeper cover depth are difficult to estimate. Accuracies of size estimation after transition period, where debonds are shown as cold spots, are relatively low. This results show that size estimation could be affected by cover depth of the debonds and the colours of the finishing materials.

\section{REFERENCES}

[1] Lai WL, Lee KK, Poon CS, et al. A study of fullfield debond behavior and durability of CFRP-concrete composite beams by pulsed infrared thermography (IRT). NDT \& E Int. 2012;52;112-121.

[2] Maldague X. Nondestructive evaluation of materials by infrared thermography. London: Springer; 1993.

[3] Avdelidis NP, Moropoulou A. Emissivity considerations in building thermography. Energy and Buildings. 2002;35;663-667.

[4] Lai WL, Lee KK, Poon CS. Validation of size estimation of debonds in external wall's composite finishes via passive Infrared thermography and a gradient algorithm. Construction and Building Materials. 2015;87;113-124. 